\title{
Intermediate Filaments in the Human Pituitary Gland: An Immunohistochemical Study
}

\author{
W.C. Halliday, S.L. Asa, K. Kovacs and B.W. Scheithauer
}

\begin{abstract}
Normal pituitaries, pituitaries showing CHC and selected adenomas were assessed for their possible content of intermediate filaments (IF), using immunohistochemical techniques. Normal pituitaries were stained for each of the five known IF (Cytokeratins (CK), glial fibrillary acidic protein (GFAP), desmin, vimentin, and neurofilaments (NF)). Desmin could not be demonstrated, and NF staining was limited to processes in the posterior gland. In serial sections, CK was demonstrated in some corticotrophs, somatotrophs, and lactotrophs. Vimentin was limited to processes in the posterior gland. Folliculo-stellate cells (FSC), demonstrated by staining for $\mathrm{S} 100$ protein, exhibited a small subpopulation staining for CK, and another subpopulation staining for GFAP. GFAP was also demonstrated in glial processes in the posterior gland. Cells showing Crooke's hyaline change stained intensely for CK. Null cell adenomas did not stain for CK. Corticotroph adenomas, somatotroph adenomas, with or without fibrous bodies, and lactotroph adenomas contain CK-immunoreactive cells. We conclude that CK is the major IF present in the anterior pituitary gland, within some normal corticotrophs, somatotrophs and lactotrophs, and also in adenomas derived from these cells.
\end{abstract}

RÉSUMÉ: Filaments intermédiaires dans l'hypophyse humaine: une étude immunohistochimique Des hypophyses normales, des hypophyses présentent des changements hyalins de Crooke (CHC) et des adénomes ont été évaluées quant à leur contenu en filaments intermédiaires (FI) au moyen de techniques immunohistochimiques. Les hypophyses normales ont été colorées pour chacun des cinq FI connus (cytokératines (CK), protéine gliale fibrillaire acide (GFAP), desmine, vimentine, et neurofilaments (NF)). La desmine n'a pu être mise en évidence et la coloration pour les NF était limitée aux terminaisons dans l'hypophyse postérieure. Dans des coupes sériées, les CK étaient présentes dans des cellules corticotrophes, somatotrophes et lactotrophes. La vimentine était limitée aux terminaisons dans l'hypophyse postérieure. Les cellules étoilées folliculaires (FSC) mises en évidence par la coloration pour la protéine S 100 , présentaient une petite sous-population qui prenait le colorant pour la GFAP. La GFAP a également été mise en évidence dans le prolongements gliaux dans l'hypophyse postérieure. Les cellules manifestant le CHC prenaient intensément la coloration pour les CK. Les adénomes à cellules nulles ne montraient pas de CK. Les adénomes corticotrophes, les adénomes somatotrophes, avec ou sans corps fibreux, et les adenomes lactotrophes contiennent des cellules CK-positives. Nous concluons que les CK sont le FI majeur présent dans l'hypophyse antérieure, dans des cellules corticotrophes, somatotrophes et lactotrophes normales et également dans des adénomes dérivés de ces cellules.

Can. J. Neurol. Sci. 1990; 17:131-136

Intermediate filaments (IFs) are a family of straight filaments with diameters ranging from 7 to $11 \mathrm{~nm}$, a size intermediate between microtubules $(24 \mathrm{~nm})$ and microfilaments $(7 \mathrm{~nm}$ and less). To date, five families of IFs $^{1}$ have been recognized; cytokeratins (CK), glial fibrillary acidic protein (GFAP), neurofilament (NF), desmin, and vimentin. High quality monoclonal antibodies are available for immunohistochemical localization of each of the IFs. The relatively limited, in some instances specific, tissue distribution of IFs have made them valuable diagnostic markers in surgical pathology. 2,3

\begin{abstract}
Cytoplasmic filaments in the size range corresponding to IFs have been identified in certain cells of the adenohypophysis and certain pituitary adenomas. Previously, the cytoplasmic filaments of adenohypophyseal cells have been divided into two classes referred to as "microfilaments", a term currently reserved for actin and similar-sized filaments. Type I microfilaments are approximately $7 \mathrm{~nm}$ in diameter (range $5.2-8.7$ ); they are present in corticotrophs and their adenomas, and they are abundant in conditions of glucocorticoid excess, giving rise to Crooke's hyaline change (CHC). Type II microfilaments
\end{abstract}

From the Departments of Pathology, University of Manitoba (W.C.H.); St. Michael's Hospital, Toronto (S.L.A., K.K.); Mayo Clinic, Rochester (B.W.S.)

Received August 8, 1989. Accepted October 24, 1989

Reprint requests to: Dr. W.C. Halliday, Department of Pathology (Neuropathology), Health Sciences Centre, MS-435-T, 820 Sherbrook Street, Winnipeg, Manitoba, Canada R3A IR9 
(approximately $11 \mathrm{~nm}$ ) are present in some somatotroph adenomas as "fibrous bodies". 4-17 Immunohistochemical studies have shown that the filaments of $\mathrm{CHC}^{18}$ and fibrous bodies, 19 found particularly in sparsely granulated somatotroph adenomas, are composed of CKs.

A review of our current knowledge of IFs in the pituitary gland made it obvious that a comprehensive survey of IFs in the pituitary gland was needed. The findings could be correlated with previous electron microscopic and immunohistochemical studies and hopefully give new perspectives, useful in studying surgical specimens or in understanding the gland's biology. Using conventional immunohistochemical techniques, normal pituitary glands, glands with $\mathrm{CHC}$ of corticotrophs and selected pituitary adenomas were stained for IFs.

\section{Material AND Methods}

Initial studies of normal pituitaries and pituitaries with $\mathrm{CHC}$ used the peroxidase antiperoxidase method as described by Sternberger. ${ }^{20}$ Subsequent studies on serially cut normal pituitaries and pituitary adenomas utilized the avidin-biotin-peroxidase complex technique (Vector Laboratories) and the streptavidin-biotin technique (Biogenex Laboratories). Normal pituitaries, the pituitaries with $\mathrm{CHC}$ and pituitary adenomas were all formalin-fixed and paraffin-embedded tissues. The normal pituitaries used for serial sectioning were fixed in Bouin's solution, and selected, normal pituitaries, to be used for vimentin staining, were fixed in absolute ethanol.

\section{Normal Pituitary Glands}

Eight autopsy pituitaries were selected retrospectively from patients in whom there was no clinical evidence or history of endocrine dysfunction. There was no history of medications

\begin{tabular}{lc}
\hline Table 1: Pituitary Adenoma & Number \\
\hline \hline Type & \\
Somatotroph & 3 \\
- densely granulated & 6 \\
- sparsely granulated with fibrous bodies & 3 \\
Lactotroph & 4 \\
Coricotroph & 5 \\
Null Cell & \\
\hline
\end{tabular}

which might have an effect on the pituitary gland. Five normal pituitary glands were obtained at the time of autopsy and fixed in Bouin's solution. Three normal autopsy pituitaries were fixed in absolute ethanol. Hematoxylin and eosin $(\mathrm{H}+\mathrm{E})$ and Mann stains confirmed a normal histology in each case.

\section{Crooke's Hyaline Change}

Ten pituitaries were selected retrospectively from patients who had been treated with corticosteroids for management of various pathological conditions.

\section{Pituitary Adenomas}

Twenty-one pituitary adenomas (see Table 1) were characterized on the basis of immunohistochemical and ultrastructural features. ${ }^{6-8,15}$

\section{Antisera, Slide Preparation and Staining Protocols}

The pituitary glands were stained with monoclonal antibodies against each of the five known intermediate filaments (IFs), (cytokeratins (CK), glial fibrillary acidic protein (GFAP), neurofilaments (NF), desmin and vimentin). In addition, pituitaries were also stained for growth hormone $(\mathrm{GH})$, prolactin (PRL), adrenocorticotrophic hormone (ACTH), $\propto$ subunit of glycoprotein hormones $(\propto-\mathrm{su})$ and $\mathrm{S} 100$ protein. The antibodies or antisera, their sources, working dilutions and controls are listed in Table 2.

The serially cut $5 \mu \mathrm{m}$ sections were numbered sequentially and stained in such a way as to give a CK stained or vimentin stained slide adjacent to a slide stained for one of GH, PRL, ACTH or $\propto$-su. In one instance, the slides on either side of a slide stained for $\$ 100$ protein were stained for CK and GFAP respectively.

\section{RESULTs}

\section{Normal Pituitary Gland}

In formalin-fixed normal pituitary glands numerous cells stained for CK. The number of positive cells varied from case to case. The results of studies using serial sections are detailed below. GFAP was present in cell processes in the posterior lobe. In addition, some cells lining small cavities in the pars intermedia and scattered cells in the anterior lobe, usually with a stellate morphology, were positive for GFAP. NF was present in

Table 2: Antisera/Antibodies, Dilutions, Controls, Sources

\begin{tabular}{ccll}
\hline \hline Monoclonal Antibody & Dilution & Control & Source \\
\hline Anti-vimentin & $1: 75$ & Meningioma & Labsystems (ORTHO) \\
-desmin & $1: 20,1: 50$ & Skeletal & \\
-GFAP & $1: 1000$ & Muscle & Astrocytoma \\
-NF (200,000 dalton) & $1: 400$ & Spinal Cord & \\
-CK (internal organ CK) & $1: 50$ & Liver &
\end{tabular}

\begin{tabular}{clll} 
Antiserum & & & \\
\hline Anti-SI00 Protein & $1: 200$ & Melanoma & DAKO \\
-PRO & $1: 300$ & Pituitary & DAKO \\
-GH & $1: 750$ & Pituitary & DAKO \\
-ACTH & $1: 300$ & Pituitary & DAKO \\
- $\alpha$ su & $1: 800$ & Pituitary & Kourides (30) \\
-CK & $1: 400,1: 100$ & Liver & Huang $(31)$ \\
\hline
\end{tabular}



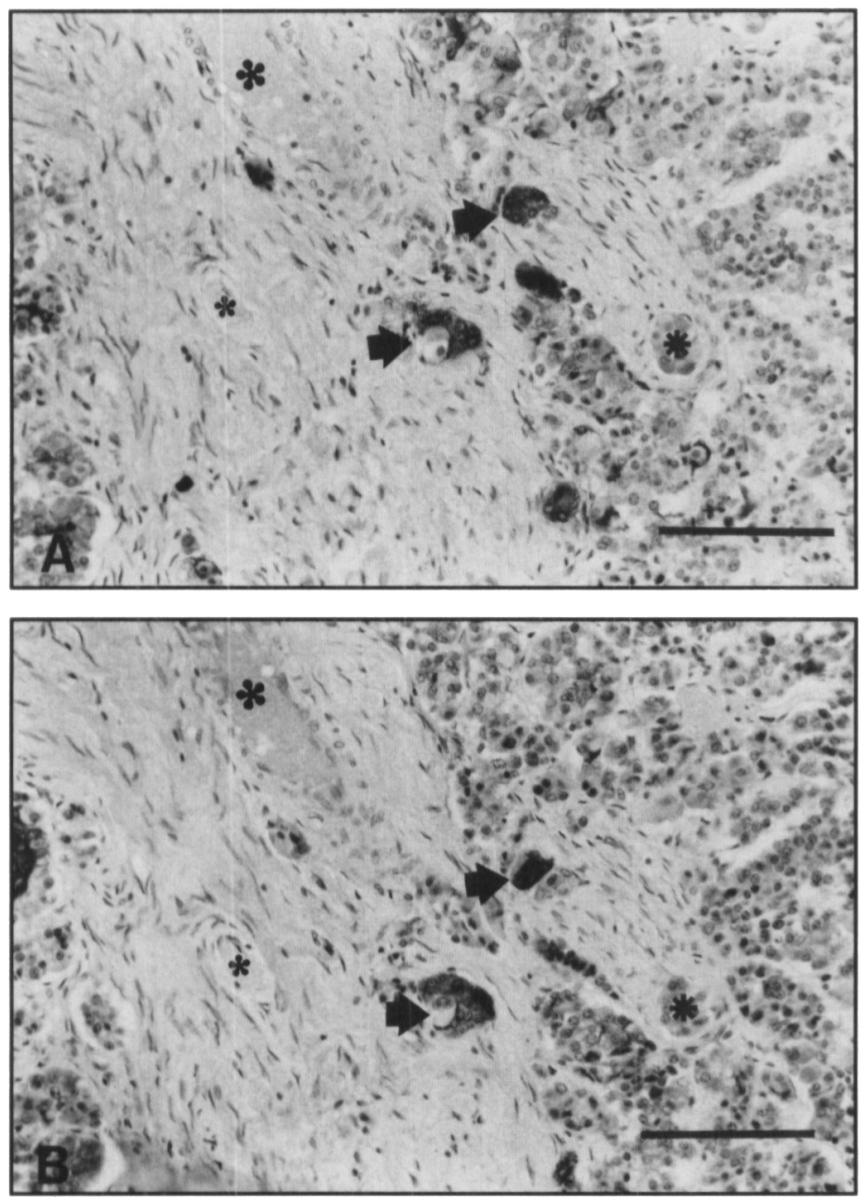

Figure IA - Immunohistochemical staining for $\$ 100$ protein is used to demonstrate folliculo-stellate cells. IB - A serial section (symbols identify the same histological landmark in each section) stained for $C K$ identifies groups of cells (arrows IA and IB) staining for both $S 100$ and $C K$. Bar $=100$ microns.

axonal processes of the posterior lobe. NF immunoreactivity was not evident in the anterior lobe. Desmin was detected in smooth muscle of vessel walls but not in pituitary cells. Vimentin could not be clearly demonstrated in any of the formalinfixed, paraffin embedded material. Ethanol-fixed glands demonstrated preserved antigenicity of vimentin. Vascular endothelium and cell processes with vimentin immunopositivity were present in the posterior lobe; immunoreactive cells were not found in the anterior pituitary.

Among each group of GH-, PRL-, and ACTH-containing cells, there was a small subpopulation which contained $\mathrm{CK}$. Cells containing $\propto$-subunit were negative. Though the number of adenohypophyseal cells staining for CK varied from case to case, no correlation with age or sex was evident.

The pattern of immunohistochemical staining for $\mathrm{CK}$ in $\mathrm{GH}$, PRL, or ACTH cells tended to be either a diffuse cytoplasmic staining or a focally dense staining on a lighter background. In the second instance, the focal condensation was either beneath the cytoplasmic membrane or adjacent to the nucleus. A pattern specific for an individual cell type was not recognized.

The number of cells in the anterior lobe containing S100 protein varied from case to case. The immunoreactive cells characteristically had a folliculo-stellate morphology with processes often extending to embrace adjacent polygonal cells. A subpopulation of these cells also contained cytokeratins (Figures $1 \mathrm{~A}$ and $\mathrm{B}$ ); a separate, much smaller subpopulation of these cells stained for GFAP (Figures $2 A$ and B).

Within the pars intermedia there were usually several cystic spaces lined by suboidal epithelium. On occasion some cells stained for ACTH; isolated examples of a single cell staining of $\mathrm{GH}$ or PRL were a rare finding. The sparsity of cells with immunopositivity for a hormone precluded an accurate correlation with serial slides stained for either S100, CK or GFAP. The latter series of slides demonstrated that the cells lining the cysts of the pars intermedia are a pleomorphic population. Some cells contained S100 and CK, others contained S100 and GFAP and some had no IF immunoreactivity, staining only for S100 protein.

\section{Crooke's Hyaline Change}

In each case studied, the cells with $\mathrm{CHC}$ were intensely positive for CK. The immunoreactivity corresponded to the hyaline area on $\mathrm{H} \& \mathrm{E}$ staining and the pale, non-granular area identified with the Mann stain. Conversely, the cells contained ACTH immunoreactivity in the granular regions and not in the hyaline areas. Corticotrophs with $\mathrm{CHC}$ were negative for GFAP, desmin and NF; vimentin stains were negative but all tissues with $\mathrm{CHC}$
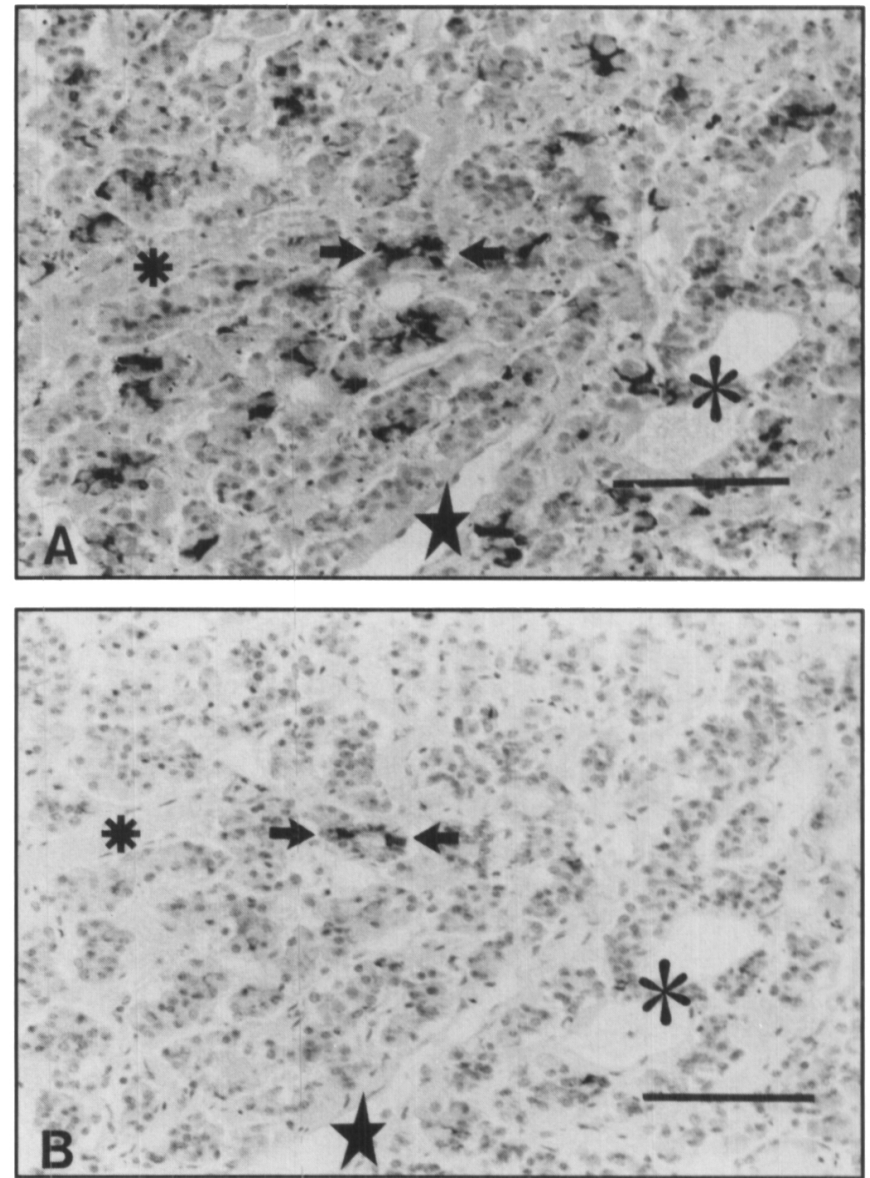

Figure $2 A-$ Immunohistochemical staining for 5100 protein is used to demonstrate folliculo-stellate cells. $2 B-A$ serial section (symbols identify the same histological landmark in each section) stained for $G F A P$ identifies a group of cells (arrow's $2 A$ and $2 B$ ) staining for both $S 100$ and GFAP. Bar $=100$ microns. 


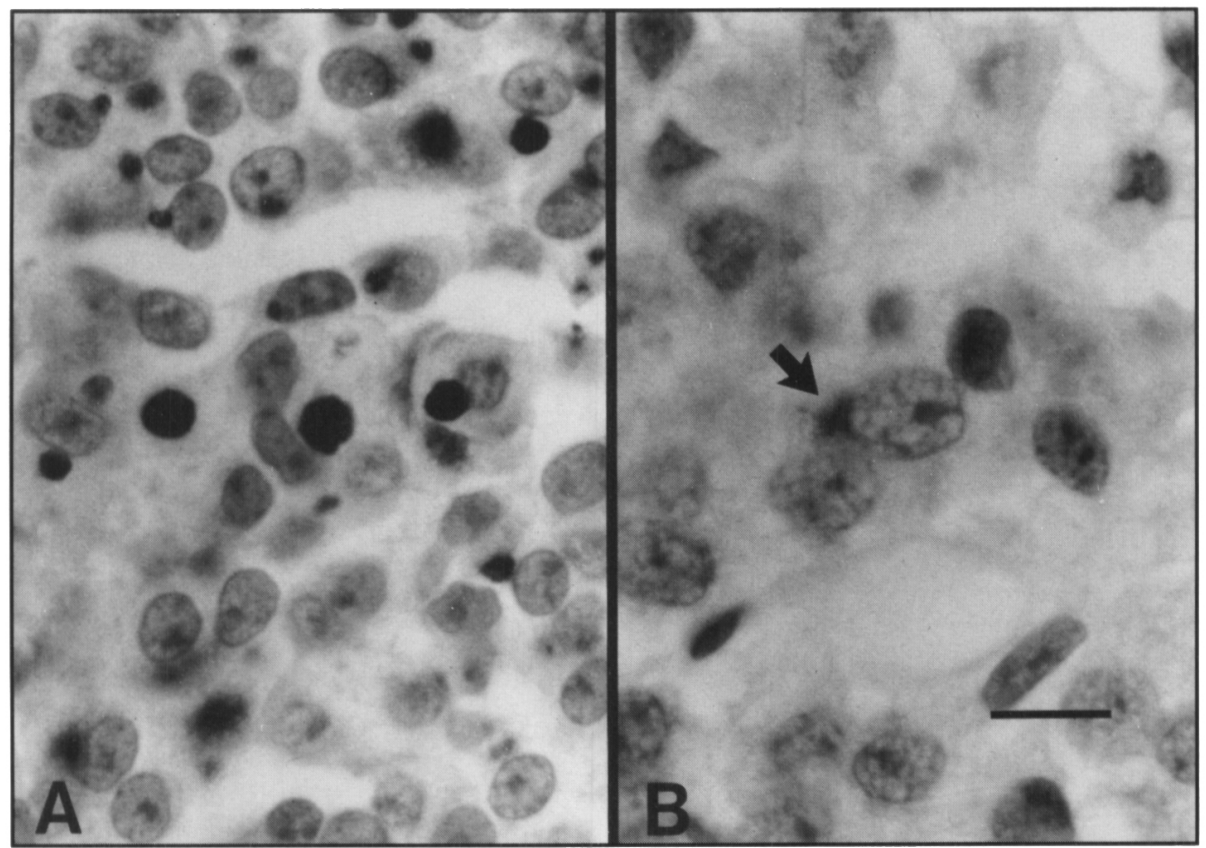

Figure $3 A-$ With immunohistochemical staining for $C K$, the fibrous bodies of sparsely granulated somatotroph adenomas characteristically stained as a globular, cytoplasmic mass. $3 B-A$ densely granulated somatotroph adenoma exhibits cells with a more diffuse cytoplasmic immunoreactivity for CK. Bar = 10 microns.

were fixed in formalin.

\section{Adenomas}

Immunopositivity for CK was detected in cells of all three densely granulated growth hormone adenomas and all six sparsely granulated somatotroph adenomas with fibrous bodies stained positive for CK (Figures $3 \mathrm{~A}$ and $\mathrm{B}$ ). A round globular positive staining cytoplasmic mass was a characteristic feature of sparsely granulated somatotroph adenomas with fibrous bodies. Further, the immunostaining varied greatly from weakly to intensely positive. Two of three lactotroph adenomas and four of four corticotroph adenomas contained cells which stained positive for $\mathrm{CK}$ (Figures $4 \mathrm{~A}$ and $\mathrm{B}$ ). Again, the number of positive cells and the degree of staining varied from adenoma to adenoma. In lactotroph, corticotroph, and densely granulated somatotroph adenomas there was a similar and more diffuse cytoplasmic staining, which contrasted with the globular pattern noted only in sparsely granulated somatotroph adenomas. None of the five null cell adenomas contained CK immunoreactivity.

GFAP, desmin and NF were not detected in tumor cells of any of the adenomas or between tumor cells indicating the lack of nerves or FSC in these lesions. Vimentin immunoreactivity could not be demonstrated in formalin-fixed material; no ethanol-fixed adenomas were available for study.

\section{Discussion}

In agreement with Höfler and co-workers, ${ }^{21}$ this study indicates that $\mathrm{CK}$ is the commonest IF in the adenohypophysis and that CK occur in some somatotrophs, lactotrophs and most corticotrophs. A specific staining pattern for CK in a particular cell type could not be substantiated. Höfler et al found glycoprotein hormone-producing cells and their adenomas to be either weakly positive or negative. Methodological differences may explain why we were not able to demonstrate CK in glycoprotein hormone-producing cells.

A subpopulation of corticotrophs, lactotrophs and somatotrophs stained for $\mathrm{CK}$. The number of immunoreactive cells varied from case to case. The functional significance of detectable IFs in adenohypophyseal cells remains unclear. The accumulation of CKs in corticotrophs associated with elevations of blood glucocorticoids, CHC, suggests that IFs may be controlled or modulated through mechanisms which are corticosteroid responsive and that IFs may accumulate under an inhibitory (i.e., non-secretory) influence. It can be speculated that the subpopulations of corticotrophs, lactotrophs and somatotrophs which stain for $\mathrm{CK}$ are not at that time secreting that hormone. The relationship between IFs and hormone secretion requires further investigation.

It is not surprising to find cells in adenomas derived from each of somatotrophs, lactotrophs and corticotrophs staining for CK. Neumann and co-workers identified the filaments associated with fibrous bodies in growth hormone-secreting adenomas as CK. ${ }^{19}$ Our investigations reveal that sparsely granulated somatotroph adenomas with fibrous bodies uniquely had CK demonstrated as a round to globular cytoplasmic mass. In densely granulated somatotroph, lactotroph and corticotroph adenomas, the cytoplasmic staining was more diffuse. In all instances, a) the number of cells staining for CK varied greatly, and b) the intensity of staining varied from weakly to intensely positive. That desmin was not detected in either the adeno- or neurohypophysis is not unexpected. This IF is thought to be restricted to developing and mature muscle cells. ${ }^{1-3}$ Similarly, it is not unexpected that NF would be limited to axonal processes in the posterior lobe. ${ }^{1-3}$

Altmannsberger and co-workers ${ }^{22}$ have noted that it is not always possible to demonstrate vimentin in formalin-fixed material and that the antigenicity of vimentin is better preserved 


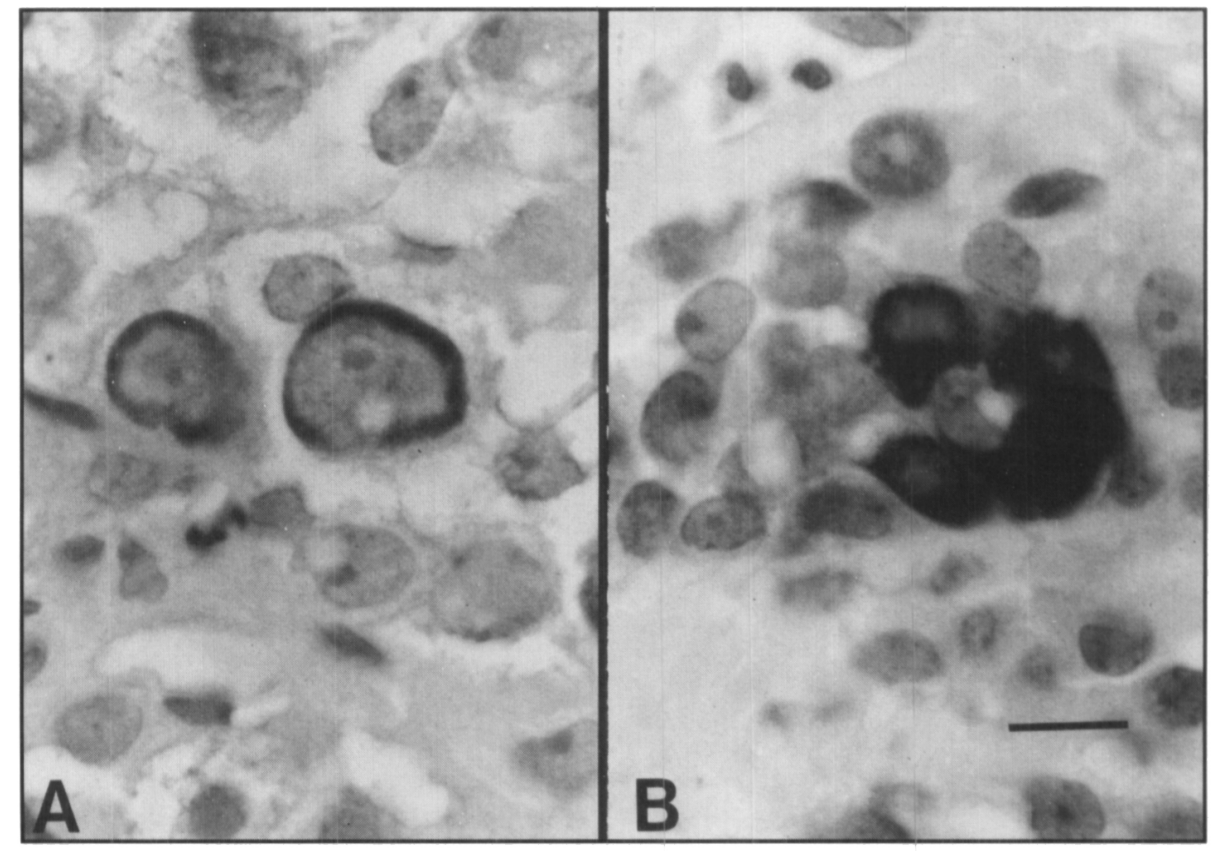

Figure $4 A-A$ corticotroph adenoma contains cells which demonstrate cytoplasmic immunoreactivity for $C K .4 B-$ Similarly, cells with intense cytoplasmic staining for $C K$ are illustrated in a lactotroph adenoma. Bar $=10$ microns.

in alcohol-fixed tissue. Although it is possible to obtain positive results when examining formalin-fixed tissue using a monoclonal antibody, ${ }^{22}$ variable results, which are difficult to interpret, represent a major problem. For this reason, three normal glands were fixed in alcohol and stained with a monoclonal antibody. In contrast to the results of Höfler and co-workers, ${ }^{24,25}$ vimentin was not detected in FSC. Vimentin was not demonstrated in adenohypophyseal cells; cell processes in the neurohypophysis contained vimentin. Vimentin can co-exist with GFAP in astrocytes ${ }^{26}$ and thus it is most likely that the staining has demonstrated glial elements in the posterior lobe. The failure to demonstrate vimentin in the adenohypophysis is not evidence that it is not there. Vimentin is present in developing tissues and its expression is "switched off" as the tissue differentiates and the definitive IF is expressed. Muscle ${ }^{27}$ and nerve 26 both demonstrate this transition during development. Thus it is conceivable that cells of the adenohypophysis may express vimentin at some stage in their development.

Velasco and co-workers ${ }^{28}$ documented the presence of GFAP in the neurohypophysis, some cells lining cysts in the intermediate lobe and scattered cells, which they felt were folliculo-stellate cells (FSC), in the adenophyophysis. Recently, Morris and Hitchcock, ${ }^{29}$ and Höfler et $\mathrm{al}^{24}$ have shown that FSC in the human adenohypophysis stain for $\mathrm{S} 100$ protein and GFAP. Our study offers both confirmation and perspective to the works noted above and adds new findings. Where the staining sequence of serial slides was GFAP, S100 and CK, it was clear that some cells containing $\mathrm{S} 100$ protein also contained GFAP or $\mathrm{CK}$ and that the number of FSC staining for $\mathrm{S} 100$ protein far exceeded the number staining for either GFAP or CK. Thus, cells with a folliculo-stellate morphology stained a) only for $\mathrm{S} 100$ protein, b) for $\mathrm{S} 100$ protein and $\mathrm{CK}$, or c) for $\mathrm{S} 100$ protein and GFAP. These results suggest that there may be 3 subpopula- tions of FSC which may have differing immunoreactivity and functions. Cells staining for GFAP could represent a supporting cell serving a function akin to astrocytes. Thus the expression of GFAP may represent an activation of the FSC to produce this IF, as has been suggested by previous investigators. ${ }^{28}$ The presence of CK, rather than GFAP, in a subpopulation of $\$ 100$ containing cells implies a different function. It can be speculated that $\mathrm{CK}$ may be the IF present in cells with cellular junctions, microvilli on their luminal surface and a more follicular arrangement. The possibility exists that the sustentacular and phagocytic functions attributed to FSC represent different populations that can be separated by their cytoplasmic IF and this should be explored further.

In summary, the filaments previously identified in nontumorous and adenomatous adenohypophyseal cells, previously called microfilaments type I and II, 15 are now known to be IFs by size criteria, and our study has confirmed that they contain CK immunoreactivity. Furthermore, cytokeratin is the major IF present in the anterior pituitary gland, being found in some somatotrophs, lactotrophs and corticotrophs. This immunoreactivity is increased in CHC and has a characteristic globular pattern in sparsely granulated somatotroph adenomas. Finally, FSC appear to be made up of three different cell populations, one containing S100 and GFAP, one S100 and CK and one staining only for $\mathrm{S} 100$ protein.

\section{ACKNOWLEDGEMENTS}

This study was supported by funds from the Dept. of Pathology. University of Manitoba, and MRC Grants MT 6349 and MA 10215

\section{REFERENCES}

1. Steinert PM, Steven AC, Roop DR. The molecular biology of intermediate filaments. Cell 1985; 42:411-419. 
2. Osborn $M$. Intermediate filaments as histologic markers: an overview. J Invest Dermatol 1983; 81 (Suppl 1): 104s-109s.

3. Osborn $\mathbf{M}$, Weber $\mathbf{K}$. Tumor diagnosis by intermediate filament typing: a novel tool for surgical pathology. Lab Invest 1983; 48: 372-394.

4. Kovacs K, Horvath E, Ilse G. Type I microfilaments in adenohypophyseal cells of the human pituitary. Microscopical Society of Canada 1975; 11: 28-29.

5. Kovacs K, Horvath E. Stratmann I.E., et al. Cytoplasmic microfilaments in the anterior lobe of the human pituitary gland. Acta Anat 1974; 87: 414-426.

6. Kovacs K, Horvath E. Morphology of adenohypophyseal cells and pituitary adenomas. I $n$ : Imura $\mathrm{H}$, ed. The Pituitary Gland. Raven Press 1985.

7. Asa SL, Kovacs K. Histological classification of pituitary disease. Clin Endocrinol Metab 1983; 12(3): 567-596.

8. Asa SL, Horvath E, Kovacks, et al. Cytology of the normal pituitary and pituitary tumors, chapter II. In: Odell WD, Nelson D, eds. Pituitary Tumors Futura Publishers, Ltd. 1984.

9. Halmi NS, McCormick WF, Decker DA. The natural history of hyalinization of ACTH-MSH cells in man. Arch Pathol 1971; 91: 318-326.

10. Schochet SS, McCormick WF, Halmi NS. Acidophil adenomas with intracytoplasmic filamentous aggregates. Arch Pathol 1972; 94: 16-22.

11. DeCicco FA, Dekker A, Yunis EJ. Fine structure of Crooke's hyaline change in the human pituitary gland. Arch Pathol 1972; 94: 65-70.

12. Kovacs K, Horvath E. Amphophil adenoma of the human pituitary gland with masses of cytoplasmic microfilaments. Endokrinologie 1974; 63(3): 402-408.

13. Robert F, Pelletier G, Hardy J. Pituitary adenomas in Cushing's disease. Arch Pathol Lab Med 1978; 102: 448-455.

14. Felix IA, Horvath E, Kovacs K. Massive Crooke's hyalinization in corticotroph cell adenomas of the human pituitary. Acta Neurochir 1981; 58: 235-243.

15. Horvath E. Kovacs K. Tumors of the pituitary gland. Atlas of Tumor Pathology, Fascicle 21, Second Series. Washington: Armed Forces Institute of Pathology, 1986.

16. Horvath E, Kovacs K. Morphogenesis and significance of fibrous bodies in human pituitary adenomas. Virchows Arch B Cell Path 1978; 27: 69-78.

17. Horvath E. Kovacs K, Singer W, et al. Acidophil stem cell adenoma of the human pituitary. Cancer 1981; 47(4): 761-771.
18. Neumann PE, Horoupian DS, Goldman JE, et al. Cytoplasmic filaments of Crooke's hyaline change belong to the cytokeratin class. Am J Physiol 1984; 116(2): 214-222.

19. Neumann PE, Goldman JE, Horoupian DS, et al. Fibrous bodies in growth hormone-secreting adenomas contain cytokeratin filaments. Arch Pathol Lab Med 1985; 109: 505-508.

20. Stemberger LA. Immunocytochemistry. 2nd ed. New York: Wiley 1979.

21. Höfler H, Denk H, Walter GF. Immunohistochemical demonstration of cytokeratins in endocrine cells of the pituitary gland and in pituitary adenomas. Virchows Arch [Pathol Anat] 1984; 404: 359-368.

22. Altmannsberger M, Osborn M, Schauer A, et al. Antibodies to different intermediate filament proteins. Cell type-specific markers in paraffin-embedded human tissues. Lab Invest 1981; 45: 427434.

23. Halliday WC, Yeger H, Duwe GF, et al. Intermediate filaments in meningiomas. J Neuropathol Exp Neurol 1985; 44(6): 617-623.

24. Höfler H. Walter GF, Denk H. Immunohistochemistry of folliculostellate cells in normal human adenohypophyses and in pituitary adenomas. Acta Neuropathol (Berl) 1984; 65: 35-40.

25. Höfler H. Denk H, Lackinger E, et al. Immunocytochemical demonstration of intermediate filament cytoskeleton proteins in human endocrine tissues and (neuro-) endocrine tumours. Virchows Arch [Pathol Anat] 1986; 409: 609-626.

26. Schnitzer J, Franke WW, Schachner M. Immunocytochemical demonstration of vimentin in astrocytes and ependymal cells of developing and adult mouse nervous system. J Cell Biol 1981; 90: 435-447.

27. Gard DL, Lazarides E. The synthesis and distribution of desmin and vimentin during myogenesis in vitro. Cell 1980; 19: 263275.

28. Velasco ME, Roessmann U, Gambetti P. The presence of glial fibrillary acidic protein in the human pituitary gland. J Neuropathol Exp Neurol 1982; 41(2): 150-163.

29. Morris CS, Hitchcock E. Immunocytochemistry of folliculostellate cells of normal and neoplastic human pituitary gland. J Clin Pathol 1985; 83: 481-488.

30. Kovacs K, Horvath E, Ryan N. Immunocytology of the human pituitary. In: DeLellis RA, ed. Diagnostic immunohistochemistry. Monographs in Diagnostic Pathology. New York: Masson 1981; 17-35.

31. Kinoff RJ, Huang S-N. Immunocytochemical and immunoelectron microscopic studies on Mallary bodies. Lab Invest 1981; 45: 491-503. 